\title{
Design thinking: guidelines for organizations
}

\author{
Pedro Ishio ${ }^{1}$, PhD Ricardo Gaspar², PhD Romulo Lins ${ }^{3}$ \\ ${ }^{1}$ Pedro Ishio, Master of Science in Engineering and Innovation Management \\ by the Federal University of $A B C$ \\ pedro.ishio@ufabc.edu.br \\ ${ }^{2}$ PhD Ricardo Gaspar, Associate Professor at the Engineering, \\ Modelling and Applied Sciences Center at the Federal University of ABC \\ ricardo.gaspar@ufabc.edu.br \\ ${ }^{3}$ PhD Romulo Gonçalves Lins, Professor at the Engineering, \\ Modelling and Applied Sciences Center at the Federal University of ABC \\ romulo.lins@ufabc.edu.br
}

\begin{abstract}
The objective of this paper is to iterate proposed functional guidelines for the assertive practice of the design thinking approach in organizational environments, and therefore to promote innovation. Considering the statement that contextual conditions directly influence innovation, three specific functional guidelines - Design conductive formalization, Responsible hierarchical presence, and Integrative functional differentiation - go through a qualitative validation. Theory triangulation is conducted through semi-structured interviews with ten experienced professionals who practice design thinking in organizational environments. After consensual assessments and value judgements through Likert scales from the interviewed participants are formalized, the functional guidelines are iterated, and it is proposed that for the practice of design thinking in organizational environments to be effective: (1) organizations must count on an ecosystem that encourages creativity and experimentation in order to stimulate employees' engagement to continuous learning in a result oriented manner; (2) organizations must promote generative sessions where collaboration and hierarchy neutralization happen counting on the presence of facilitators that make sure objectives are reached according to the businesses' purposes; (3) organizations must contemplate human-centered work that is integrative and heterogeneous in order to increase the assertiveness of proposed solutions due to the diversity, knowledge and perspectives of everyone involved.
\end{abstract}

Keywords: design thinking, design process, collaborative design, innovation, innovation management 


\section{Introduction}

According to Lockwood (2009), we are living in the best time so far for the creation of new problem-solving methods. That is because we need new and transformative business strategies that are based on human needs, not just financial analysis, and design thinking may be the ideal approach to achieving them. In addition to that, the design strategic influence has been growing (Banerjee et al., 2013), and in business management design thinking has been considered the best way to push creativity and innovation forward (Johansson-Sköldberg et al., 2013).

Definitions about innovation claim the importance and necessity to exploit the aspects of novelty, not only its invention (Tidd et al., 2013). That is because innovation is not simply coming up with good ideas, but also putting them into practice (Hargadon, 2003). In order to put ideas into practice, the context inevitably has to be considered. The environment is recognized as one of the most important contextual factors that influence innovation (Tornatzky et al., 1990). Thus, organizational structures constitute important factors regarding the rhythm and direction of innovation (Teece, 1996).

Publications about the design thinking practice considering the organizational environments, that is, contemplating what must be considered in terms of structures, processes, organizational culture and other peculiarities regarding the organizational ambience are scarce (Correia et al., 2017). Accordingly, the objective of this paper is to contribute to this body of knowledge by iterating proposed functional guidelines for the assertive practice of design thinking in organizational environments, and therefore to promote innovation.

\section{Design Thinking}

According to Fleury et al. (2016)., design thinking is a human-centered approach applied to wicked problem-solving that starts with the understanding of different users' perspectives. The definition by the authors also includes that the approach involves multidisciplinary teamwork based on the balance between cooperation-conflict among different actors in a co-creation process, in which the conflict of ideas become the genesis for the establishment of innovative solutions.

Lockwood (2009) defines design thinking as an essentially human-centered innovation process that emphasizes observation, collaboration, fast learning, visualization of ideas, rapid concept prototyping, and business strategy with the objective of integrating consumers, designers, and businesspeople to product, service, or even business design. Additionally, Brown (2009) defends that design thinking is a powerful approach to innovation, besides effective, broadly accessible, and possible to be integrated into all aspects of business and society as it can be useful to generate breakthrough ideas.

Fleury et al. (2016) state that although design thinking is nowadays seen as powerful for the development of disruptive innovations, it is still unclear what are the consolidated results obtained with the application of this approach in distinct organizational contexts. Therefore, according to the authors, the findings from empirical research have to be systematized in order to evidence the best practices for design thinking, both in quantitative and qualitative terms. This qualitative study contributes to this matter by iterating proposed functional guidelines about how to increase the effectiveness of the design thinking practice while taking into consideration the practicing environment and its characteristics according to experienced professionals. 


\section{Organizational Structures}

According to Ackoff (1981), the environment is a complex system that consists of multiple types and dimensions. In terms of innovation, organizational variables have been widely studied and are considered very important as determinants to innovation (Damanpour, 1991).

Organizational structures are what define the way responsibility and power are allocated, and work procedures are carried out, among organizational members (Blau, 1970).

Through a literature review, Damanpour (1991) documented organizational structures as being the concepts related to administrative intensity, centralization, external communication, formalization, functional differentiation, hierarchy, internal communication, managerial attitude toward change, managerial tenure, professionalism, slack resources, specialization, and technical knowledge resources. Additionally, Daft (1995) includes to the list of organizational structures the concepts of complexity, personnel ratios, and standardization.

Also, through a literary review, Correia et al. (2018), established a relationship between the design thinking practice and three specific organizational structures - formalization, hierarchy, and functional differentiation. From the study, three functional guidelines for the assertive practice of design thinking in organizational environments were proposed, as seen in Table 1 .

Table 1. Functional Guidelines, based on Correia et al. (2018)

\section{Functional guidelines}

Design conductive formalization

Employees must be provided with clearly specified rules and procedures that encourage creative, exploratory, and risk friendly work and learning in a design conductive ecosystem so engagement, motivation and productivity can be increased.

Responsible hierarchical presence

Managerial responsibilities and roles must be designated so strategic decisions can be made quickly and co-creation can work.

\section{Integrative functional differentiation}

Functional differentiation has to contemplate integrative, human-centered, and collaborative work, with the existence of interdisciplinary teams for a rich mix of expertise and points of view so opportunities can be better seized.

\section{Precision, Credibility, and Transferability}

In order to validate the proposed functional guidelines in terms of precision (Winter, 2000), credibility, and transferability (Hoepfl, 1997), the following conditions need to be considered. The study in question has a qualitative nature. Qualitative research, broadly defined, means any kind of research that produces findings not reached by means of statistical procedures or quantification (Strauss and Corbin, 1990).

Patton (1990) defends that triangulation represents an effective way to validate qualitative research. Triangulation encompasses the use of different approaches to avoid distortions that may be caused due to the use of methods, theories or researchers (Günther, 2006). There are 
several types of triangulation. In order to validate the functional guidelines in question, the theory triangulation (Guion, 2002) was chosen.

According to Guion (2002), theory triangulation involves the use of multiple professionals to interpret a given information set so diverse perspectives are contemplated. By using theory triangulation, different people can contribute to different but equally valid representations about the analyzed subject. In addition, according to Malterud (2001), in qualitative research, different approaches to the same subject may result in a larger and richer understanding of it.

\subsection{Semi-structured interviews and theory triangulation}

Taking into consideration the theory triangulation (Guion, 2002), ten semi-structured interviews with experienced professionals were conducted. Therefore, different individuals could approach different representations, although equally valid, regarding the proposed functional guidelines discussed. Through the interviews, a richer understanding about the proposed functional guidelines was obtained, which is encouraged by Malterud (2001).

In semi-structured interviews, researchers explore the experience of the interviewed and the meanings attributed to them that are pertinent to the research through open answered questions, usually in individual conversations (Tong et al., 2007).

\subsubsection{Sample characteristics}

In interviews, participants that share particular characteristics and can potentially provide rich, relevant, and diverse information are selected (Tong et al., 2007). Thus, 10 professionals who worked in organizations in at least managerial roles and practiced design thinking were selected. 10 semi-structured interviews were conducted personally and individually in São Paulo, Brazil, with the participants in their workplace or its surroundings. The names of the interviewed professionals were kept confidential and the aliases P1, P2, P3, P4, P5, P6, P7. P8, P9, and P10 were adopted in order to ensure their identification and the description of their characteristics that were relevant to the present study. These interviews contemplated questions about the history of the participants with design thinking, the learning related to the theme, and the motivations behind choosing design thinking as an approach with which to work with. Furthermore, the following themes were discussed: the adoption of human-centered methods by organizations, difficulties in practicing design thinking, conductive environments to the practice of the approach, interdisciplinarity, stakeholders' participation in design thinking processes, autonomy and the role of top management regarding design thinking.

As seen in Table 2, Table 3, Table 4, and Table 5, the participants' roles were collected alongside the classification by size of the company they work for, as their years of experience in the job market, and the number of organizations they practiced design thinking in so their familiarity with the approach could be assessed.

Table 2. Roles

\begin{tabular}{|l|l|}
\hline \multicolumn{2}{|l|}{ Roles } \\
\hline P1 & New Media and Innovation Manager \\
\hline P2 & Innovation and New Business Manager \\
\hline P3 & Project Leader, Service Designer and Business Designer \\
\hline
\end{tabular}




\begin{tabular}{|l|l|}
\hline P4 & User Experience Manager \\
\hline P5 & Senior Designer Manager \\
\hline P6 & Consumer Experience Manager \\
\hline P7 & Design Director \\
\hline P8 & Branding and Innovation Director \\
\hline P9 & Strategic Designer and Innovation Manager \\
\hline P10 & Group Director \\
\hline
\end{tabular}

Table 3. Classification of the company

\begin{tabular}{|l|l|}
\hline \multicolumn{2}{|l|}{ Classification of the company } \\
\hline P1 & Domestic Large-Sized Enterprise \\
\hline P2 & Multinational Large-Sized Enterprise \\
\hline P3 & International Medium-Sized Enterprise \\
\hline P4 & Multinational Large-Sized Enterprise \\
\hline P5 & Multinational Large-Sized Enterprise \\
\hline P6 & Multinational Large-Sized Enterprise \\
\hline P7 & Multinational Large-Sized Enterprise \\
\hline P8 & Domestic Small-Sized Business \\
\hline P9 & Multinational Large-Sized Enterprise \\
\hline P10 & Multinational Large-Sized Enterprise \\
\hline
\end{tabular}

Table 4. Years of experience in the job market

Years of experience in the job market

\begin{tabular}{|l|l|l|l|l|l|l|l|l|l|l|}
\hline 11 to 15 & P1 & P2 & P3 & P4 & & P6 & & & & \\
\hline 16 to 20 & & & & & & & P7 & & & P10 \\
\hline 21 ato 25 & & & & & P5 & & & & P9 & \\
\hline More than 30 & & & & & & & & P8 & & \\
\hline
\end{tabular}


Table 5. Quantity of organizations the participants practiced design thinking

\begin{tabular}{|l|l|l|l|l|l|l|l|l|l|l|}
\hline Quantity of organizations the participants practiced design thinking \\
\hline 1 & & & & & P5 & & & & & \\
\hline 2 & & P2 & & P4 & & P6 & & & & \\
\hline 3 & & & & & & & P7 & P8 & & \\
\hline 4 & & & & & & & & & P9 & P10 \\
\hline More than 10 & P1 & & P3 & & & & & & & \\
\hline
\end{tabular}

According to Amabile (1996), people that work in certain domains are the ones that possess the greater capacity to recognize and assess creativity in their particular domains. The author defends that as long as there is a considerable level of agreement between the individual judgements made by the experts in determined domains, combinations of their assessments can be used to recognize, evaluate and measure levels of pertinence, accuracy, value, and meaning. In order to evaluate the proposed functional guidelines in terms or pertinence, accuracy, value, and meaning, ten experienced design thinking practitioners were chosen so their assessment could enrich the proposed functional guidelines.

The sample characteristics guarantee a profound, diverse, and mature knowledge regarding the relationship between design thinking and organizational environments, making it possible that different perspectives regarding the same subject are contemplated, resulting in a richer and higher understanding of the proposed functional guidelines, the subject in question, which is encouraged by Malterud (2001) when it comes to validation of qualitative research and is stimulated by Guion (2002) regarding theory triangulation.

\subsection{Likert Scale}

According to Göb et al. (2007), Rensis Likert was responsible for introducing a measuring scale for opinion assessment. In this scale, an individual is confronted with statements so that essentially value judgements can be made. These value judgements must reflect the perceptions of the certain individual about their reality or their psychic dispositions. In the Likert scale, the individual is invited to define their assessment about a statement by choosing a degree within a determined scale. After the interviews, the participants were confronted with the three proposed functional guidelines and it was asked that they choose between strongly disagree, disagree, neutral, agree, and strongly agree. The results can be seen in the following tables.

Table 6. Likert scale - Design conductive formalization

\section{Likert scale - Design conductive formalization}

Employees must be provided with clearly specified rules and procedures that encourage creative, exploratory, and risk friendly work and learning in a design conductive ecosystem so engagement, motivation and productivity can be increased.

Strongly disagree 


\begin{tabular}{|l|l|l|l|l|l|l|l|l|l|l|}
\hline Disagree & & & P3 & & & & & & & \\
\hline Neutral & & & & & & & & & & \\
\hline Agree & P1 & & & & P5 & & P7 & & & \\
\hline Strongly agree & & P2 & & P4 & & P6 & & P8 & P9 & P10 \\
\hline
\end{tabular}

Table 7. Likert scale - Responsible hierarchical presence

\section{Likert scale - Responsible hierarchical presence}

Managerial responsibilities and roles must be designated so strategic decisions can be made quickly and cocreation can work.

\begin{tabular}{|l|l|l|l|l|l|l|l|l|l|l|}
\hline Strongly disagree & & & & & & P6 & & & & \\
\hline Disagree & & & P3 & & & & & & & \\
\hline Neutral & & & & & & & & & & \\
\hline Agree & P1 & & & & P5 & & & P8 & & P10 \\
\hline Strongly agree & & P2 & & P4 & & & P7 & & P9 & \\
\hline
\end{tabular}

Table 8. Likert scale - Integrative functional differentiation

Likert scale - Integrative functional differentiation
Functional differentiation has to contemplate integrative, human-centered, and collaborative work, with the
existence of interdisciplinary teams for a rich mix of expertise and points of view so opportunities can be better
seized

The interviewed professionals showed themselves adequate for the validation of the proposed functional guidelines in terms of pertinence, accuracy, value, and meaning due to their roles and experience regarding the design thinking practice in organizational environments.

The proposed functional guideline that had the professionals strongly agreeing the most was the one named Integrative functional differentiation. It is possible to assume that the guideline 
is pertinent and meaningful. More importantly, one of the participants disagreed with the proposed guideline, which makes it possible for it to be improved.

The functional guideline named Responsible hierarchical presence was the one to receive the highest number of disagreements between the three of them, a total of two. Despite the fact that this specific functional guideline had four participants agreeing with its affirmations and four other participants strongly agreeing with its propositions, which corroborates to the pertinence and meaning of its pronouncements, it is evident that it can be refined.

The Likert scale for Design conductive formalization also showed that the proposed functional guideline can be improved, although the rate of agreeing revealed its affirmations can be considered pertinent, accurate, and valuable.

\section{Guidelines iterated}

The result of the validation of the proposed functional guidelines for the assertive design thinking practice into organizations is elucidated below and contemplates its iteration considering the opinions, notions and convictions of the expert interviewed professionals according to a systematic analysis of qualitative data. The process of systematic analysis of qualitative data (Miles and Huberman, 1994) adopt the immersion and crystallization analysis style (Crabtree and Miller, 1999). In using this method, the researcher organizes data by examining the content thoroughly and then crystallizing out the most significant aspects.

\subsection{Iterative formalization}

According to $\mathrm{P} 9$, to make the design thinking practice effective, the organization must have a conductive environment to design not with clear rules, but also a culture that encourages its empowerment. According to $\mathrm{P} 2$, in order to establish a culture that encourages innovation by design it is necessary to establish processes that facilitate it. According to the participant, from the moment you create processes and triggers encouraging innovation, people change the way they work, and the innovation culture starts being incorporated naturally.

According to $\mathrm{P} 3$, it is necessary to connect all people who participate in initiatives that involve design thinking with business strategies. According to the participant, collaborators who have goals regarding their own departments are less likely to commit to innovation. When they face the company strategy and are given the possibility to participate in it, collaborators increase their commitment to it.

According to $\mathrm{P} 1$, companies that contemplate design thinking must have a more systematic performance evaluation. The participant defends that companies that work with personnel evaluations in which grades are attributed to employees according only to their competencies by the technical aspect, not necessarily considering the behavioral aspect, face difficulties in grouping expertise and capabilities. Additionally, According to P5, it is important that the employees responsible for Human Resources formalize ways for employees to spend time on initiatives that involve collaboration. In addition, according to the participant, it is also the role of top management to engage their teams in innovation projects. P8 also states that organizations cannot be afraid of taking risks and making mistakes for innovation to occur.

Considering the statements of the participants regarding the concepts of formalization as organizational structure and the exercise of design thinking, it is possible to state that organizations must count on an ecosystem that encourages creativity and experimentation in order to stimulate employees' engagement to continuous learning in a result-oriented manner. 


\subsection{Collaborative hierarchy neutralization}

According to $\mathrm{P} 1$, what really matters during design thinking processes is what each individual has to contribute, not their job roles. According to the participant, when top management participates in the processes the results are much more effective, although more difficult to achieve. P2 believes that top management employees must understand their roles in the process. According to the participant, there are certain times when they can contribute more assertively. Thus, $\mathrm{P} 2$ believes that the participation of these professionals is more effective at times when decision making is necessary. According to P4, when managers do not participate in design decisions, the decisions can lose strength. Additionally, P6 believes that executives help to promote initiatives by being a part of it.

According to P8, it is very common for employees to feel inhibited by the presence of top management in co-creation sessions. P10 corroborates to this statement by defending that depending on the project stage, inhibitions happen more frequently, especially in early stage workshops.

For P2, the ideal is to really ensure the presence of top management in a strategic way. In order to ensure that the purposes are achieved, according to the participant, it is necessary to have a very experienced facilitator who can walk all stakeholders through the process at the appropriate moments. According to the participant, the facilitator should be responsible for knowing when each person will be of greater or lesser importance, in addition to where there is the possibility of inhibiting others or favoring them.

Additionally, P1 believes that it is the facilitator's role to ensure everyone's understanding about not letting roles interfere in the integration of people and the flow of ideas in addition to extracting the best from each of the members of the workshop sessions that involve design thinking.

Considering the statements of the participants regarding the concepts of hierarchy as organizational structure and the exercise of design thinking, it is possible to state that organizations must promote generative sessions where collaboration and hierarchy neutralization happen counting on the presence of facilitators that make sure objectives are reached according to the businesses' purposes.

\subsection{Empathetic functional differentiation}

According to $\mathrm{P} 1$, it is necessary to have people from different professional backgrounds participating in initiatives that use the design thinking practice to ensure a much more complete, holistic and systemic look at the initiatives in question. P2 corroborates to this statement by saying that increasing human diversity in design thinking practices are fundamental.

P6 also considers the multiplicity of disciplines necessary for design thinking to be effective. According to the participant, contributions from different human sources are relevant to the processes because of the different knowledge, different stories and precepts, which contribute to a more collective and multidisciplinary construction of knowledge.

According to P8, this importance is due to the variety of perspectives. According to the participant, when working with a multidisciplinary team, one ends up having different points of view to solving problems that alone would not have been possible due to singular personal limitations and knowledge.

Considering the statements of the participants regarding the concepts of functional differentiation as organizational structure and the exercise of design thinking, it is possible to state that for the practice of design thinking to be effective, organizations must contemplate human-centered work that is integrative and heterogeneous in order to increase the assertiveness of proposed solutions due to the diversity, knowledge and perspectives of everyone involved. 


\subsection{Iteration, Collaboration, and Empathy}

After using the method of theory triangulation (Guion, 2002), which is encouraged by Malterud (2001) in qualitative research, a consensual assessment (Amabile, 1996) was conducted in order to evaluate the proposed functional guidelines in terms of pertinence, accuracy, value and meaning. The evaluators, qualified experienced professionals, design thinking practitioners, gave their feedback through in-depth semi-structured interviews and Likert scales.

The three functional guidelines proposed were iterated according to the enrichment of the understanding about the relationship between design thinking and organizational structures through the interviewed professionals.

The functional guidelines proposed according to a literary review (Correia et al., 2018) between the design thinking and organizational structures can be seen and compared to the functional guidelines iterated after validations with specialists below, on the Table 9.

Table 9. Functional guidelines iterated

\begin{tabular}{|c|c|}
\hline \multicolumn{2}{|l|}{ Functional guidelines iterated } \\
\hline Previous Functional guidelines & Functional guidelines iterated \\
\hline Design conductive formalization & Iterative formalization \\
\hline $\begin{array}{l}\text { Employees must be provided with clearly } \\
\text { specified rules and procedures that } \\
\text { encourage creative, exploratory, and risk } \\
\text { friendly work and learning in a design } \\
\text { conductive ecosystem so engagement, } \\
\text { motivation and productivity can be } \\
\text { increased. }\end{array}$ & $\begin{array}{l}\text { Organizations must count on an ecosystem } \\
\text { that encourages creativity and } \\
\text { experimentation in order to stimulate } \\
\text { employees' engagement to continuous } \\
\text { learning in a result-oriented manner. }\end{array}$ \\
\hline Responsible hierarchical presence & Collaborative hierarchy neutralization \\
\hline $\begin{array}{l}\text { Managerial responsibilities and roles must } \\
\text { be designated so strategic decisions can be } \\
\text { made quickly and co-creation can work. }\end{array}$ & $\begin{array}{l}\text { Organizations must promote generative } \\
\text { sessions where collaboration and hierarchy } \\
\text { neutralization happen counting on the } \\
\text { presence of facilitators that make sure } \\
\text { objectives are reached according to the } \\
\text { businesses' purposes. }\end{array}$ \\
\hline Integrative functional differentiation & Empathetic functional differentiation \\
\hline $\begin{array}{l}\text { Functional differentiation has to } \\
\text { contemplate integrative, human-centered, } \\
\text { and collaborative work, with the existence } \\
\text { of interdisciplinary teams for a rich mix of } \\
\text { expertise and points of view so } \\
\text { opportunities can be better seized. }\end{array}$ & $\begin{array}{l}\text { Organizations must contemplate human- } \\
\text { centered work that is integrative and } \\
\text { heterogeneous in order to increase the } \\
\text { assertiveness of proposed solutions due to the } \\
\text { diversity, knowledge and perspectives of } \\
\text { everyone involved. }\end{array}$ \\
\hline
\end{tabular}




\section{Discussions, limitations and future work}

The study in question has known limitations. According to Malterud (2001) the objective of research in general is to produce information that is shared and applied beyond the research domain, keeping in mind that no study, regardless of the applied methods, is capable of providing universally applicable results. Additionally, according to Amabile (1996), only time and historical consensus can tell if the research was truly creative or just eccentric.

Malterud (2001) states that the intentional choosing of a research sample is usually done so quality material is obtained. To the study in question, in order to evaluate the proposed functional guidelines in terms or pertinence, accuracy, value, and meaning, ten experienced design thinking practitioners were chosen so their assessment could enrich the proposed functional guidelines. Although the sample characteristics guarantee a profound, diverse, and mature knowledge regarding the relationship between design thinking in organizational environments due to their experience and responsibility, choosing professionals in at least managerial roles leaves professionals with minor positions out of the study, even though their assessment could also enrich and contribute to the findings. Also, the present study was conducted in São Paulo, Brazil, with only Brazilian design thinking practitioners. Although most of the sample worked at the time of the research for multinational large-sized enterprises, it is encouraged future research to be done contemplating different ethnicities and nationalities in order to neutralize possible cultural biases regarding the obtained results.

Due to the established delimitation in order to achieve the proposed objectives, three organizational structures were considered - formalization, hierarchy, and functional differentiation. For a richer understanding of the relationship between design thinking and its environment in a holistic manner, it is also suggested that future studies should be conducted considering all the organizational structures proposed by Damanpour (1991) and Daft (1995). Nevertheless, the iterated functional guidelines proposed in this paper might represent a contribution to a better understanding of design thinking and its context.

\section{References}

Ackoff, R. L. (1981). The art and science of mess management. Interfaces, 11(1), 20-26.

Amabile, T. M., Conti, R., Coon, H., Lazenby, J., \& Herron, M. (1996). Assessing the work environment for creativity. Academy of management journal, 39(5), 1154-1184.

Banerjee, S., Secchi, S., Fargione, J., Polasky, S., \& Kraft, S. (2013). How to sell ecosystem services: a guide for designing new markets. Frontiers in Ecology and the Environment, 11(6), 297-304.

Blau, P. M. (1970). A formal theory of differentiation in organizations. American sociological review, 201-218

Brown, T. (2009). Change by design.

Correia, P. T I., Gaspar, R., Lins, R. G. (2017). Design thinking and organizational structures: a structured research with foccus on innovation (translated from portuguese). Congresso Internacional de Empreendedorismo e Inovação.

Correia, P. T. I., Gaspar, R., \& Lins, R. (2018). Design thinking for organizations: functional guidelines. DS 91: Proceedings of NordDesign 2018, Linköping, Sweden, 14th-17th August 2018.

Crabtree, B. F., \& Miller, W. L. (Eds.). (1999). Doing qualitative research. sage publications.

Daft, R. (1995). Organization and design. 
Damanpour, F. (1991). Organizational innovation: A meta-analysis of effects of determinants and moderators. Academy of management journal, 34(3), 555-590.

Fleury, A. L., Stabile, H., \& Carvalho, M. M. (2016). An overview of the literature on design thinking: trends and contributions. International Journal of Engineering Education, 32(4), 1704-1718.

Guion, L. A. (2002). Triangulation: Establishing the validity of qualitative studies.

Günther, H. (2006). Qualitative research versus quantitative research: is this the question?. Psycholohy: theory and research, 22(2), 201-209.

Göb, R., McCollin, C., \& Ramalhoto, M. F. (2007). Ordinal methodology in the analysis of Likert scales. Quality \& Quantity, 41(5), 601-626.

Hargadon, A. (2003). How breakthroughs happen: The surprising truth about how companies innovate. Harvard Business Press.

Hoepfl, M. C. (1997). Choosing qualitative research: A primer for technology education researchers.

Johansson-Sköldberg, U., Woodilla, J., \& Çetinkaya, M. (2013). Design thinking: past, present and possible futures. Creativity and Innovation Management, 22(2), 121-146.

Lockwood, T. (2009). Transition: How to become a more design-minded organization. Design Management Review, 20(3), 28-37.

Malterud, K. (2001). Qualitative research: standards, challenges, and guidelines. The lancet, 358(9280), 483-488.

Miles, M. B., \& Huberman, A. M. (1994). Qualitative data analysis: An expanded sourcebook. sage.

Patton, M. Q. (1990). Qualitative evaluation and research methods. SAGE Publications, Inc.

Strauss, A., \& Corbin, J. M. (1990). Basics of qualitative research: Grounded theory procedures and techniques. Sage Publications, Inc.

Teece, D. J. (1996). Firm organization, industrial structure, and technological innovation. Journal of economic behavior \& organization, 31(2), 193-224.

Tidd, J., Bessant, J., \& Pavitt, K. (2013). Managing innovation. Hoboken.

Tong, A., Sainsbury, P., \& Craig, J. (2007). Consolidated criteria for reporting qualitative research (COREQ): a 32-item checklist for interviews and focus groups. International journal for quality in health care, 19(6), 349-357.

Tornatzky, L. G., Fleischer, M., \& Chakrabarti, A. K. (1990). Processes of technological innovation. Lexington Books.

Winter, S. G. (2000). The satisficing principle in capability learning. Strategic management journal, 981-996. 